\title{
Foucault: Les aveux de la chair e a genealogia do sujeito desejante
}

\section{Carolina de Souza Noto \\ Universidade Federal de Santa Catarina | Santa Catarina | Brasil}

Michel Foucault (2018), Histoire de la sexualité IV. Les aveux de la chair, Ed. Frédéric Gros, Paris: Gallimard.

$\mathrm{Na}$ introdução de $O$ uso dos prazeres, segundo volume da História da sexualidade, publicado meses antes de sua morte, ocorrida em junho de 1984, Foucault nos oferece uma das mais esclarecedoras exposições de sua própria produção intelectual. Deixa claro que seu projeto deve ser compreendido, antes de tudo, como uma história das formas da experiência ou ainda como análise da singularidade histórica da experiência em suas variantes: experiência da loucura na Idade Clássica, da delinquência e da sexualidade na Modernidade. Por experiência, diz Foucault, entenda-se aí "a correlação, em uma cultura, entre domínios de saber, tipos de normatividade e formas de subjetividade" (1984, p. IO). A experiência é, pois, a correlação nós mesmos e certa relação que temos com a verdade e com as normas sociais. Uma história das formas da experiência deve mostrar, em cada momento singular, como se dá essa correlação. E a História da sexualidade em particular deve dar conta de compreender a correlação entre verdade, norma e relação a si, implicada na maneira como a nossa cultura, em diferentes momentos, problematizou e vivenciou os prazeres, os atos e os desejos sexuais.

É esse horizonte que devemos ter em vista para compreender o significado do quarto volume da História da sexualidade, Les aveux de la chair, publicado na França em fevereiro de 2018. Como esclarece Frédéric Gros em sua apresentação, este volume estava praticamente pronto para ser publicado, em 198I, quando Foucault, advertido por Paul Veyne, julgou que ele só teria sentido em um projeto mais amplo, que considerasse, ao lado da transição do Paganismo ao Cristianismo, as técnicas de constituição da subjetividade na Antiguidade clássica e tardia (às quais são dedicados os volumes 2 e 3 da História da sexualidade, respectivamente $O$ uso dos prazeres e $O$ cuidado de si). Colhido pela morte, Foucault não pôde retomar o volume 4, mas, felizmente, o manuscrito original foi preservado. Por razôes 
que Gros não deixa claro, o pedido de Foucault para que não houvessem edições póstumas de seus manuscritos parece ter caducado, e a História da sexualidade pode agora ser apreciada, finalmente, como um projeto unitário e acabado.

Como quase todos os escritos de Foucault, Les aveux de la chair seguramente despertará o interesse de uma diversa gama de leitores. Os mais desconfiados serão talvez os especialistas, como o latinista ou o medievalista. E haveria muito a debater quanto à precisão ou acuidade das análises textuais de Foucault. Mas o interesse do livro reside algures. Trata-se, como indica o próprio título, de recuperar, através dos textos, a experiência cristã da carne, no período entre os séculos II e IV d.C. Aos que leem Foucault como historiador estrito, vale a advertência dada por ele mesmo na introdução ao segundo volume da tetralogia: "Os estudos que se seguem, assim como outros que empreendi anteriormente, são estudos de 'história' pelos campos que tratam e pelas referências que tomam; mas não são trabalhos de 'historiador'" (1984, p. I6) Foucault faz genealogia e, como tal, vale-se da história, como ele mesmo diz, para saber "em que medida o trabalho de pensar sua própria história pode afastar o pensamento daquilo que ele pensa silenciosamente, permite que ele pense diferentemente" (Ibid., p. 17).

Mas de que aspecto da atualidade se trata, na História da sexualidade, de fazer a genealogia? Daquele que diz respeito à nossa experiência com o corpo, o sexo, os prazeres, e os desejos. O primeiro volume dessa história, A vontade de saber, surgido em 1976, ensinou que a experiência do sexual se configura na Modernidade, de modo geral, como uma experiência da sexualidade. Uma experiência complexa, que, como indicamos acima, comporta três níveis diferentes de relação. No nível epistemológico, a experiência da sexualidade implica certo tipo de conhecimento de si que toma os desejos sexuais como objeto privilegiado a ser conhecido, já que se acredita que eles sejam reveladores da verdade de nosso próprio ser. No nível político ou intersubjetivo das normas, a experiência da sexualidade implica uma relação severa com a lei: a crença é a de que tanto a subjetividade quanto a sociedade só se estruturam se formos capazes de interditar e reprimir nossos desejos sexuais. Por fim, no nível da ética, para que o sujeito seja capaz de conhecer a verdade de seus desejos e submetê-los às interdiçōes necessárias, é preciso realizar tanto a prática do exame de consciência quanto a prática de dizer a um outro o que se descobre dentro de si mesmo.

Não é difícil de perceber que o diagnóstico de Modernidade realizado em 1976 anuncia certa proximidade entre a psicanálise e a tradição cristã: ambas tomam o desejo sexual como problema central do ser do homem, pensam o desejo numa relação intrínseca com a lei e impõem ao sujeito a prática da confissão. Em $A$ vontade de saber, contudo, as proximidades ficam no nível vago da sugestão; não há verificação que possa sustentar a hipótese. Muito mais do que uma genealogia do 
sujeito do desejo — que apenas será empreendida a partir do segundo volume —, o que se vê é a arqueologia desse tipo de sujeito: um mapeamento (ou cartografia) da situação atual do problema. A grande lição de $A$ vontade de saber, que será desenvolvida por Foucault nos cursos do Collège de France que se seguem à publicação do livro (Segurança, território e população e O nascimento da biopolítica), é a de que a noção de sujeito de desejo vigora não só no campo da psicanálise, mas também em outros campos de saber, e sobretudo, no campo da política, das formas de poder e das formas de governo. As teses mais gerais sobre "biopoder" e "biopolítica" estão sustentadas pela hipótese da centralidade do sujeito de desejo na modernidade. Hipótese essa que Foucault percorrerá genealogicamente a partir dos cursos da década de 8o (O governo dos vivos; Subjetividade e verdade; $A$ hermenêutica do sujeito; $O$ governo de si e dos outros e $O$ governo de si e dos outros: a coragem da verdade), bem como dos volumes II, III e IV da História da sexualidade.

O quarto volume, embora tenha sido o último a ser publicado, foi, como dissemos, o primeiro a ser redigido. Estima-se que Foucault começara a escrevê-lo entre 1979 e 1980, concomitantemente ao curso O governo dos vivos, que se propõe uma análise histórica acerca da relação entre sujeito e verdade no cristianismo. Percorridos os discursos e as formas de poder modernas, baseadas na ideia do sujeito de desejo, era preciso, pois, percorrer a genealogia desse tipo de sujeito. Antes, portanto, de chegar à cultura greco-romana e encontrar ali um contraponto ao modo moderno de problematizar as questôes relativas ao sexo, Foucault passa pela cultura cristã, e encontra entre elas mais continuidades do que descontinuidades.

O genealogista, acostumado a enfatizar os cortes e rupturas da história, esforçase, em Les aveux de la chair, por encontrar, no início da Idade Média, a origem da nossa experiência moderna da sexualidade. É claro que a experiência da carne não é idêntica à da sexualidade, assim como a experiência grega dos prazeres não se reduz a nenhuma delas. Mas, em vez de assinalar as diferenças que separam a cultura cristã da nossa, como faz com a análise da cultura greco-romana, que aparece quase como antípoda ao nosso modo moderno de viver, Foucault encontra, no Cristianismo dos primeiros séculos, o nascimento do que estará no centro de nossa experiência moderna: o desejo.

Para Foucault, o cristianismo é, desde os primórdios, uma religião que impõe a seus seguidores uma "obrigação com relação à verdade": obrigação de permanecer fiel a um conjunto de dogmas e aos livros que são a fonte da verdade desses dogmas, de aceitar as decisões das autoridades em matéria de verdade, de mostrar que se acredita nessas verdades e obrigaçôes, de revelar a verdade acerca de si mesmo. É precisamente essa última modalidade de "obrigação de verdade" que Foucault vê em cena nos ritos de penitência e que tem como fim último evitar a excomunhão dos pecadores ou, de maneira positiva, a reintegração e reconciliação dos pecadores 
à Igreja. De acordo com Foucault, o Cristianismo primitivo é marcado por dois modelos de penitência que implicam a manifestação da verdade de si e a renúncia de si mesmo. De um lado, há o rito que autores latinos como Tertuliano, Cipriano e Jerônimo, chamaram de exomologesis: uma forma de revelar publicamente a verdade de si mesmo por meio de atos espetaculares de mortificação do próprio corpo; de outro, a exogoresis, descrita por João Crisóstemo e João Cassiano, que exige dos fiéis um cuidadoso exame de consciência e uma exaustiva verbalização a outrem de seus próprios pensamentos. De um lado, o que Foucault chamará de faire-vrai, que tem como objetivo expurgar os pecados do corpo, e que, nesse sentido, é uma prática de renúncia e de mortificação do próprio corpo; de outro lado, o dire-vrai, que, mais do que mortificação somática, quer renunciar a certos pensamentos dúbios, enganosos ou ilusórios. De um lado, a manifestação e a renúncia da verdade daquilo que se é somaticamente; de outro, a verbalização e a renúncia daquilo que se pensa.

De acordo com Foucault, o que se percebe ao longo da história do Cristianismo é a prevalência do dire-vrai em detrimento do faire-vrai; nesse sentido, a experiência moderna da sexualidade está mais próxima da exogoresis do que da exomologesis, de um exaustivo exame dos pensamentos mais secretos e da confissão do que de uma encenação pública do corpo pecador. Ou seja: herdamos da cultura cristã a desconfiança incessante em relação a nossos próprios pensamentos, mais do que o hábito de mortificação e renúncia do próprio corpo. A carne, e não tanto o corpo, é o objeto-problema do Cristianismo e, por extensão, nosso problema atual. A carne não como corpo vulnerável às vicissitudes sensíveis, mas como corpo sensível, habitado por pensamentos e lembranças, e por uma espécie bem peculiar de desejo: a libido. Desejo relativo às coisas do corpo, é certo, mas que é da ordem do espírito e do pensamento. Faz-se presente nos sonhos, nas lembranças e imagens que se propagam no espírito e dominam a vontade racional; ou, como diz João Cassiano, toma de súbito os pensamentos de um homem com imagens de uma mulher, começando pela de sua mãe, depois a de sua irmã, e assim por diante.

No contexto da tradição monástica, observa Foucault, o sujeito virtuoso é capaz não apenas de dominar os vícios do corpo por meio dos exercícios de contenção e abstenção, mas também de vencer e dominar seus desejos mais íntimos; não somente de evitar o ato sexual, mas também de eliminar, por meio do exaustivo exame de consciência e da confissão, todo tipo de concupiscência. É interessante botar que a castidade, nesse sentido, não se reconhece pela ausência da fornicação propriamente dita, mas, sobretudo, pela ausência da polução noturna e dos sonhos eróticos.

Foucault propõe que se entenda a moral sexual cristã não tanto como uma moral centrada na interdição de certos atos sexuais, mas como uma moral que põe 
no centro da discussão o problema do desejo sexual. Na contramão das análises psicanalíticas e antropológicas que situam a proibição do incesto no âmago da experiência sexual, Foucault se esforça em reconhecer, na origem da nossa cultura, uma forma de experiência distanciada de uma lógica econômica dos atos ou dos prazeres de uma lógica da interdição dos atos. Interessa-lhe, pois, mostrar que a forma atual da experiência da sexualidade é devedora de uma economia libidinal e de uma hermenêutica do desejo. De acordo com Foucault, mais do que problematizar os atos e os prazeres sexuais, nossa cultura problematiza os desejos; mais do que a proibição de certos atos, ela nos impõe a interpretação, a decifração e a confissão dos próprios desejos: "uma objetivação indefinida de si por si", como ele diz no final do segundo capítulo de Les aveux de la chair (2018, p. 245).

A retomada de textos sobre o casamento aponta para a mesma questão. Centrado nas análises de santo Agostinho sobre o matrimônio, Foucault procura mostrar que nelas também está em jogo uma problematização do desejo sexual e da libido. O casamento é, em essência, uma limitação. Mas, enquanto no mundo pagão as regras de união conjugal visavam sobretudo propiciar uma vida mais tranquila, longe da agitação do corpo e de certas práticas viciosas, assim como a diversificação das relaçôes, na medida em que proíbe os incestos, no Cristianismo é dada a cada indivíduo a responsabilidade de gerir seus próprios pensamentos relativos ao desejo. Torna-se uma obrigação, dentro do casamento, "regrar a economia do desejo e da concupiscência” (Foucault, 20I8, p. 273), conhecer a verdade de seus próprios desejos e saber reconhecer quais são legítimos e quais não. Para Foucault, o que ocorre assim é uma juridização das relaçōes matrimoniais e sexuais; uma espécie de internalização da regra, que impõe a cada um o dever de se tornar soberano sobre os movimentos involuntários de sua própria libido. Com isso, assegura Foucault, vemos entrar em cena na história do Ocidente uma união que irá vigor até a moral sexual moderna, entre sujeito de desejo e sujeito de direito. E é com este diagnóstico que nosso autor encerra sua genealogia: "Uma recomposição se fez em torno daquilo que poderíamos chamar, em oposição à economia do prazer paroxístico, a analítica do sujeito da concupiscência. Estão ligados aí, por laços que nossa cultura mais estreitou do que desfez, o sexo, a verdade e o direito" (Ibid., p. 36I).

Recomenda-se aos psicanalistas que se preparem para a leitura de Les aveux de la chair. Com esse livro temos, ao que parece, um novo capítulo do embate de Foucault com a psicanálise. Debruçando-se sobre o texto, caberá ao leitor refletir sobre os possíveis contatos entre a genealogia do sujeito de desejo e o saber freudiano, e perguntar-se não somente pelo alcance e a legitimidade de suas colocações, mas também pelas possíveis mudanças de pontos de vista do filósofo. Afinal, se é conhecido o elogio que, em As palavras e as coisas, Foucault fizera à 
psicanálise em sua vertente estrutural, fica a questão de saber se, com este quarto volume da História da sexualidade, também a psicanálise lacaniana não estaria sendo colocada em questão.

\section{Referências}

Foucault, Michel (1984), Histoire de la sexualité II. L'usage des plaisirs, Paris: Gallimard.

Foucault, Michel (200I). Dits et écrits II, Paris: Gallimard.

Foucault, Michel (2018), Histoire de la sexualité IV. Les aveux de la chair, Ed. Frédéric Gros, Paris: Gallimard. 